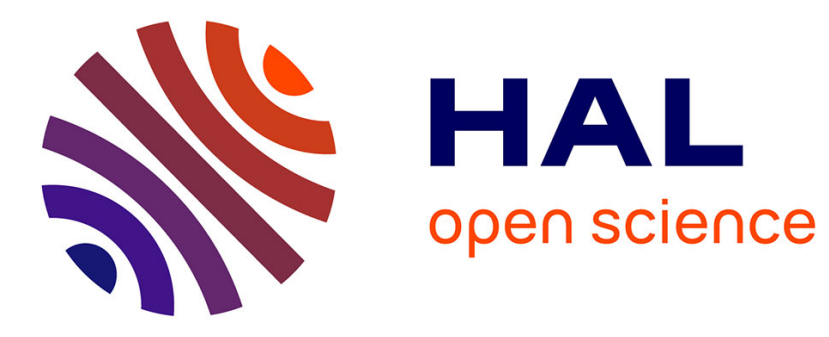

\title{
Genetic variation in genes of the fatty acid synthesis pathway and breast cancer risk
}

Daniele Campa, James Mckay, Olga Sinilnikova, Anika Hüsing, Ulla Vogel, Rikke Dalgaard Hansen, Kim Overvad, Petra Mariann Witt, Françoise Clavel-Chapelon, Marie-Christine Boutron-Ruault, et al.

\section{To cite this version:}

Daniele Campa, James Mckay, Olga Sinilnikova, Anika Hüsing, Ulla Vogel, et al.. Genetic variation in genes of the fatty acid synthesis pathway and breast cancer risk. Breast Cancer Research and Treatment, 2009, 118 (3), pp.565-574. 10.1007/s10549-009-0347-8 . hal-00535342

\section{HAL Id: hal-00535342 \\ https://hal.science/hal-00535342}

Submitted on 11 Nov 2010

HAL is a multi-disciplinary open access archive for the deposit and dissemination of scientific research documents, whether they are published or not. The documents may come from teaching and research institutions in France or abroad, or from public or private research centers.
L'archive ouverte pluridisciplinaire HAL, est destinée au dépôt et à la diffusion de documents scientifiques de niveau recherche, publiés ou non, émanant des établissements d'enseignement et de recherche français ou étrangers, des laboratoires publics ou privés. 


\title{
Genetic variation in genes of the fatty acid synthesis pathway and breast cancer risk
}

\author{
Daniele Campa · James McKay · Olga Sinilnikova · Anika Hüsing · Ulla Vogel · Rikke Dalgaard Hansen · \\ Kim Overvad · Petra Mariann Witt · Françoise Clavel-Chapelon - Marie-Christine Boutron-Ruault • \\ Veronique Chajes · Sabine Rohrmann · Jenny Chang-Claude · Heiner Boeing · Eva Fisher · \\ Antonia Trichopoulou · Dimitrios Trichopoulos · Domenico Palli $\cdot$ Anna Villarini · \\ Carlotta Sacerdote - Amalia Mattiello - Rosario Tumino - Petra H. M. Peeters · Carla H. van Gils • \\ H. Bas Bueno-de-Mesquita · Eiliv Lund · María Dolores Chirlaque · Núria Sala $\cdot$ Laudina Rodriguez Suarez \\ Aurelio Barricarte · Miren Dorronsoro · Maria-José Sánchez · Per Lenner · Göran Hallmans · \\ Kostas Tsilidis · Sheila Bingham · Kay-Tee Khaw · Valentina Gallo · Teresa Norat • \\ Elio Riboli · Sabina Rinaldi · Gilbert Lenoir · Sean V. Tavtigian · Federico Canzian • \\ Rudolf Kaaks
}

Received: 9 February 2009/Accepted: 11 February 2009/Published online: 28 February 2009

(C) Springer Science+Business Media, LLC. 2009

\begin{abstract}
Fatty acid synthase (FAS) is the major enzyme of lipogenesis. It catalyzes the NADPH-dependent condensation of acetyl-CoA and malonyl-CoA to produce palmitic acid. Transcription of the FAS gene is controlled synergistically by the transcription factors ChREBP (carbohydrate response element-binding protein), which is induced by glucose, and SREBP-1 (sterol response element-binding protein-1), which is stimulated by insulin
\end{abstract}

D. Campa · A. Hüsing · S. Rohrmann - J. Chang-Claude ·

F. Canzian · R. Kaaks $(\bowtie)$

Department of Cancer Epidemiology, German Cancer Research

Center (DKFZ), Im Neuenheimer Feld 280, 69120 Heidelberg,

Germany

e-mail: r.kaaks@dkfz.de

D. Campa

University of Pisa, Pisa, Italy

J. McKay $\cdot$ V. Chajes $\cdot$ S. Rinaldi $\cdot$ S. V. Tavtigian

International Agency for Research on Cancer, Lyon, France

O. Sinilnikova

Hospices Civils de Lyon/Centre Léon Bérard, CNRS-Université

Claude Bernard UMR5201, Lyon, France

\section{U. Vogel}

National Food Institute, Technical University of Denmark,

Copenhagen, Denmark

R. D. Hansen

Danish Cancer Society, Copenhagen, Denmark through the PI3K/Akt signal transduction pathway. We investigated whether the genetic variability of the genes encoding for ChREBP, SREBP and FAS (respectively, $M L X I P L, S R E B F 1$ and FASN) is related to breast cancer risk and body-mass index (BMI) by studying 1,294 breast cancer cases and 2,452 controls from the European Prospective Investigation on Cancer (EPIC). We resequenced the FAS gene and combined information of SNPs found by

\author{
K. Overvad · P. M. Witt \\ Aarhus University Hospital, Aalborg, Denmark \\ F. Clavel-Chapelon - M.-C. Boutron-Ruault · V. Chajes · \\ G. Lenoir \\ Insitut Gustave Roussy, Villejuif, France \\ H. Boeing · E. Fisher \\ German Institute of Human Nutrition, Potsdam-Rehbruecke, \\ Germany \\ A. Trichopoulou \\ Department of Hygiene and Epidemiology, Medical School, \\ University of Athens, Athens, Greece \\ D. Trichopoulos \\ Department of Epidemiology, Havard School of Public Health, \\ Boston, MA, USA \\ D. Palli \\ Cancer Research and Prevention Institute (ISPO), Florence, Italy
}


resequencing and SNPs from public databases. Using a tagging approach and selecting 20 SNPs, we covered all the common genetic variation of these genes. In this study we were not able to find any statistically significant association between the SNPs in the FAS, ChREBP and SREPB-1 genes and an increased risk of breast cancer overall and by subgroups of age, menopausal status, hormone replacement therapy (HRT) use or BMI. On the other hand, we found that two SNPs in FASN were associated with BMI.

Keywords Fatty acid synthase .

Carbohydrate response element-binding protein .

Sterol response element-binding protein-1 - Breast cancer . Susceptibility to cancer $\cdot$ Body-mass index

\section{Introduction}

International comparison suggests that one of the key factors underlying the high incidence of breast cancer (BC) in industrially developed countries is a Western lifestyle, characterized by low rates of energy expenditure and a high-energy diet, rich in saturated fats, refined carbohydrates and animal protein. However, the physiologic mechanisms of this relationship are poorly understood. Various hormonal and metabolic factors have been postulated to mediate the effects of a Western nutritional

\author{
A. Villarini \\ Istituto Nazionale dei Tumori (IRCCS), Milan, Italy \\ C. Sacerdote \\ CPO Piemonte, Torino, Italy
}

\author{
A. Mattiello \\ Federico II University, Naples, Italy \\ R. Tumino \\ Azienda Ospedaliera “Civile M.P. Arezzo”, Ragusa, Italy \\ P. H. M. Peeters - C. H. van Gils \\ Julius Center, University Medical Center, Utrecht, The \\ Netherlands \\ H. Bas Bueno-de-Mesquita \\ National Institute for Public Health and the Environment, \\ Bilthoven, The Netherlands \\ E. Lund \\ Institute of Community Medicine University of Troms $\varnothing$, \\ Troms $\emptyset$, Norway \\ M. D. Chirlaque \\ Murcia Health Council, Murcia, Spain \\ N. Sala \\ Catalan Institute of Oncology, Barcelona, Spain
}

lifestyle on $\mathrm{BC}$ risk [1-7]. Breast cancer risk appears to be increased among women who have elevated plasma levels of insulin-like growth factor-I (IGF-I) [1, 2, 4, 5, 7-10]. Excess energy intake and obesity also cause insulin resistance, which is associated with elevated blood levels of glucose and insulin [1, 3-6, 8, 11-13]. In turn, elevated plasma levels of glucose [12] and insulin [3, 14] have been implicated as possible risk factors for both pre- and postmenopausal BC.

Fatty acid synthase (FAS) is the major enzyme of lipogenesis. It catalyzes the NADPH-dependent condensation of acetyl-CoA and malonyl-CoA to produce predominantly the 16-carbon saturated free palmitic acid [15]. Transcription of the FAS gene is controlled synergistically by the transcription factors ChREBP (carbohydrate response elementbinding protein) and SREBP-1 (sterol response elementbinding protein-1). ChREBP binds directly to the endogenous promoter of the FAS gene in a glucose-dependent but insulin-independent manner and is absolutely required for its induction by glucose [16]. Sterol-responsive element binding protein-1 (SREBP-1) is an important transcription factor responsible for lipid accumulation in pancreatic islets in response to high glucose and insulin, through stimulation of acetyl-CoA carboxylase-1 and FAS [17, 18]. It is stimulated by insulin through the PI3K/Akt signal transduction pathway $[19,20]$. Moreover, SREBP-1 inhibition also abolishes the induction of FAS promoter.

\section{R. Suarez}

Consejería de Salud y Servicios Sanitarios Principado de Asturias, Oviedo, Spain

A. Barricarte

Public Health Institute of Navarra, Pamplona, Spain

M. Dorronsoro

Public Health Department of Gipuzkoa and CIBER de

Epidemiología y Salud Pública (CIBERESP), San Sebastian, Spain

M.-J. Sánchez

Andalusian School of Public Health and CIBERESP, Granada, Spain

P. Lenner · G. Hallmans

Umeå University, Umeå, Sweden

K. Tsilidis

University of Oxford, Oxford, UK

S. Bingham $\cdot$ K.-T. Khaw

University of Cambridge, Cambridge, UK

V. Gallo $\cdot$ T. Norat $\cdot$ E. Riboli

Imperial College, London, UK 
The FAS gene is highly up-regulated in tumor cells of the breast, as well as colon, prostate, ovary and endometrium [21-25], although this gene is expressed at minimum or undetectable level in most normal tissues. Therefore, FAS overexpression is considered to be one of the most common molecular changes in cancer cells [22, 24, 26-28]. Importantly, treatment of tumor cells with pharmacologic inhibitors of FAS leads to cell cycle arrest, followed by apoptosis of the tumor cells [29]. Moreover, FAS inhibitors have been shown to delay progression of breast and ovarian tumor xenografts, and to induce apoptosis of breast carcinoma cells [15, 23, 30-33]. Thus, the early activation of FAS in malignant and pre-malignant cells could represent a necessary survival strategy, which occurs to compensate for an insufficiency of both oxygen and dietary fatty acids due, for example, to lack of angiogenesis [34]. Thereafter, high levels of FAS are maintained in coordination with increased demand for fatty acid metabolism and/or membrane synthesis in response to cancer-related overexpression of growth factors and/or growth factor receptors [34]. Moreover, FAS hyperactivity and overexpression preferentially occur in the aggressive varieties of cancer and serve as an independent prognostic indicator of adverse clinical outcome [34].

The above observations led us to hypothesize that ChREBP, SREBP, and FAS, the key molecules involved in cellular fatty acid synthesis, may be centrally implicated in mammary gland carcinogenesis, and that polymorphic alleles of their encoding genes that modify their expression or activity confer altered BC susceptibility. In this report we investigated the genetic variability of the genes encoding for ChREBP, SREBP and FAS. We tested association of tagging SNPs in the three candidate genes with $\mathrm{BC}$ risk in a study of 1,294 invasive BC cases and 2,452 controls nested within the European Prospective Investigation into Cancer and Nutrition (EPIC). Since weight gain and obesity are well-known risk factors for postmenopausal $\mathrm{BC}$ [35], we have tested association of tagging SNPs in our three candidate genes with body-mass index (BMI) as well. To our knowledge this is the first report on polymorphisms of these genes and $\mathrm{BC}$ risk.

\section{Materials and methods}

\section{The EPIC cohort}

A fully detailed description of the EPIC cohort has been published elsewhere [36]. Briefly, EPIC consists of about 370,000 women and 150,000 men, aged 35-69, recruited between 1992 and 2005 in 10 Western European countries.

The vast majority ( $>97 \%$ ) of subjects recruited in the EPIC cohort are of European ('Caucasian') origin. All
EPIC study subjects provided anthropometric measurements (height, weight, and waist and hip circumferences) and extensive, standardized questionnaire information about medical history, diet, physical activity, smoking, and other lifestyle factors. Women also answered questions about menstrual and reproductive history, hysterectomy, ovariectomy, and use of exogenous hormones for contraception or treatment of menopausal symptoms. About 260,000 women and 140,000 men provided a blood sample.

Cases of cancer occurring after recruitment into the cohort and blood donation are identified through local and national cancer registries in 7 of the 10 countries, and in France, Germany, and Greece by a combination of contacts with national health insurances and/or active follow-up through the study subjects or their next of kin. Follow-up on vital status is achieved through record linkage with mortality registries.

Selection of case and control subjects

Case subjects were selected among women who developed BC after blood collection. Control subjects (1-2 controls per case) were selected randomly by incidence density sampling, matching the cases for centre of recruitment, age at blood donation, duration of follow-up, menopausal status at the time of blood donation and use of exogenous hormones. This study did not include women who were using hormone replacement therapy (HRT) at the time of blood donation. A total of 1,294 invasive BC cases and 2,452 controls were included in the present study. Each control should have been free of cancer up to the duration of follow-up of the index case. The study was approved by the ethical review boards of the International Agency for Research on Cancer, and of the collaborating institutions responsible for subject recruitment in each of the EPIC recruitment centres.

Resequencing analysis

The coding exons flanked by approximately $30 \mathrm{bp}$ of proximal intronic sequence, $5^{\prime} \mathrm{UTR}$, and proximal promoters of FASN were resequenced on 46 samples of BC cases of Caucasian origin not carriers of germline BRCA1/ BRCA2 mutations, using previously established procedures [37]. The genomic sequences of each locus of interest were downloaded from the UC Santa Cruz genome browser (http://genome.ucsc.edu/) (Sequences of the mutation screening primers and experimental conditions are available upon request). Sequencing reaction products were electrophoresed on a Spectrumedix capillary sequencer.

The resulting chromatograms were analyzed using the program Java SnpScreen (S. V. Tavtigian, unpublished). 
The program aligns all of the chromatograms to the canonical text sequence of each amplicon, normalizes the signal strength from all of the chromatograms, and then displays them as aligned forward-reverse chromatogram pairs. Potentially heterozygous positions are spotted, based on the joint data from the target sequence and each forward and reverse chromatogram pair.

\section{Selection of tagging SNPs}

We aimed at surveying the entire set of common genetic variants in the FASN, MLXIPL and SREBFl genes. We followed a tagging approach [38]. Gene regions were defined as the sequence between the beginning of the first known exon and the end of the last known exon. When an LD block covering a part of the gene extended outside the gene we also considered any additional sequence to include the whole block. See Figs. 1, 2 and 3 for the exact regions that were considered. We included all polymorphisms in each gene region with minor allele frequency $(\mathrm{MAF}) \geq$ 5\% in Caucasians from the International HapMap Project (version 22; http://www.hapmap.org) and, for the FASN gene, from our resequencing work. The SNPs detected by resequencing were genotyped in the HapMap Caucasian samples. Tagging SNPs were selected with the use of the Tagger program within Haploview (http://www.broad. mit.edu/mpg/haploview/; http://www.broad.mit.edu/mpg/ tagger/; [39]), using pairwise tagging with a minimum $r^{2}$ of 0.8. We used, as input for Tagger, genotypes downloaded from the HapMap database and genotypes of our resequencing SNPs typed on HapMap samples.

\section{DNA extraction and genotyping}

DNA was extracted from blood samples on an Autopure instrument (Qiagen, Hilden, Germany) with Puregene chemistry (Qiagen, Hilden, Germany). The order of DNAs from cases and controls was randomized on PCR plates in order to ensure that an equal number of cases and controls could be analyzed simultaneously. All the genotyping was carried out using the Taqman assay. The MGB Taqman probes and primers were synthesized by Applied Biosystems (Foster City, CA). The reaction mix included $5 \mathrm{ng}$ genomic DNA, 10 pmol each primer, 2 pmol each probe

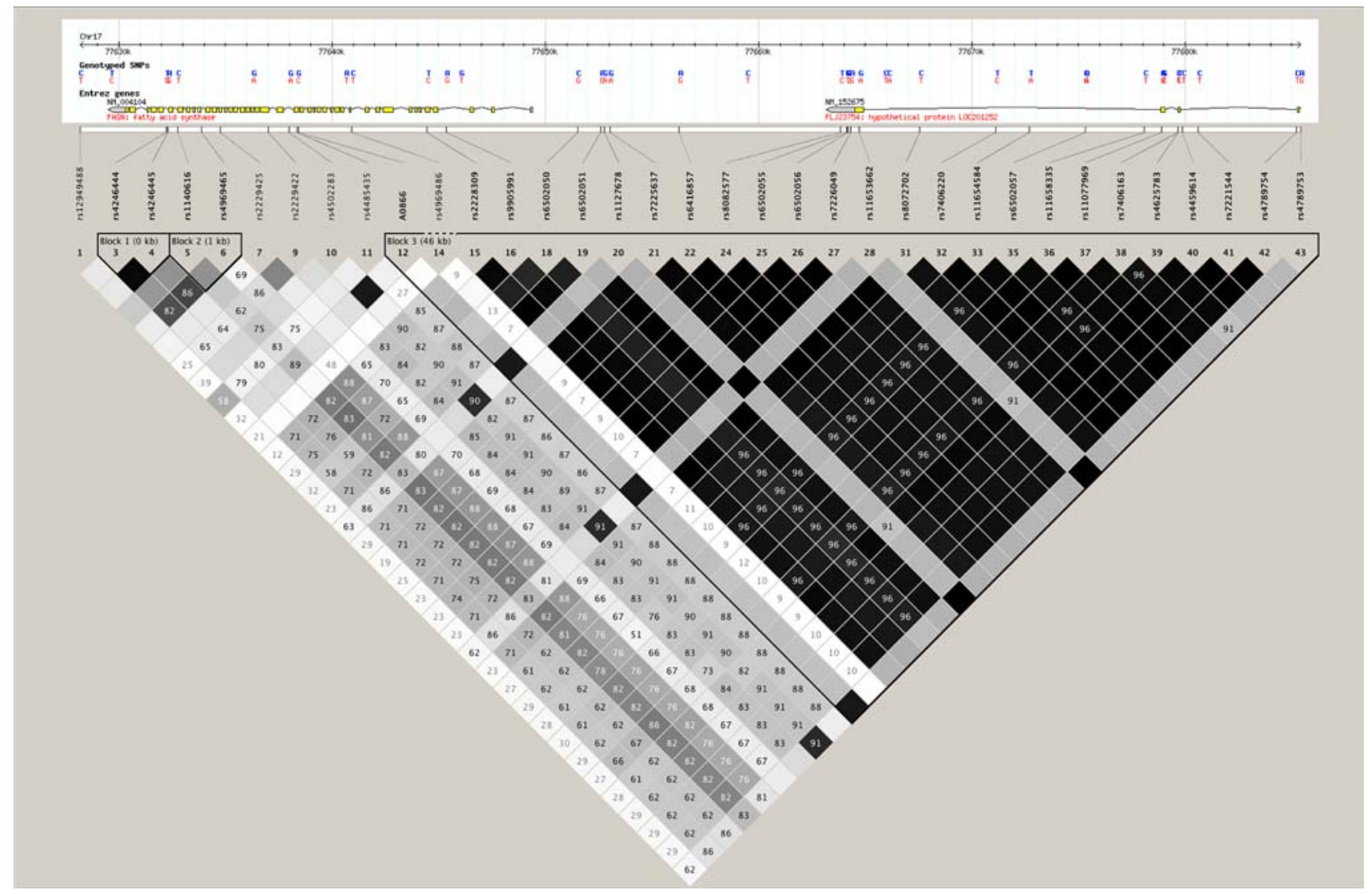

Fig. 1 FASN gene and its SNPs. From top to bottom, schematic representation of the gene (boxes represent exons, lines represent introns), position of the SNPs in the region, LD structure of the gene region (color intensity is proportional to $r^{2}$, while numbers represent
$D^{\prime}$; squares where numbers are not reported have $D^{\prime}=100 \%$ ). LD blocks covering regions larger than $10 \mathrm{~kb}$ outside genes were kept intact when they overlapped parts of the gene or the promoter region 
Fig. $2 M L X I P L$ gene and its SNPs. For details, see Fig. 1

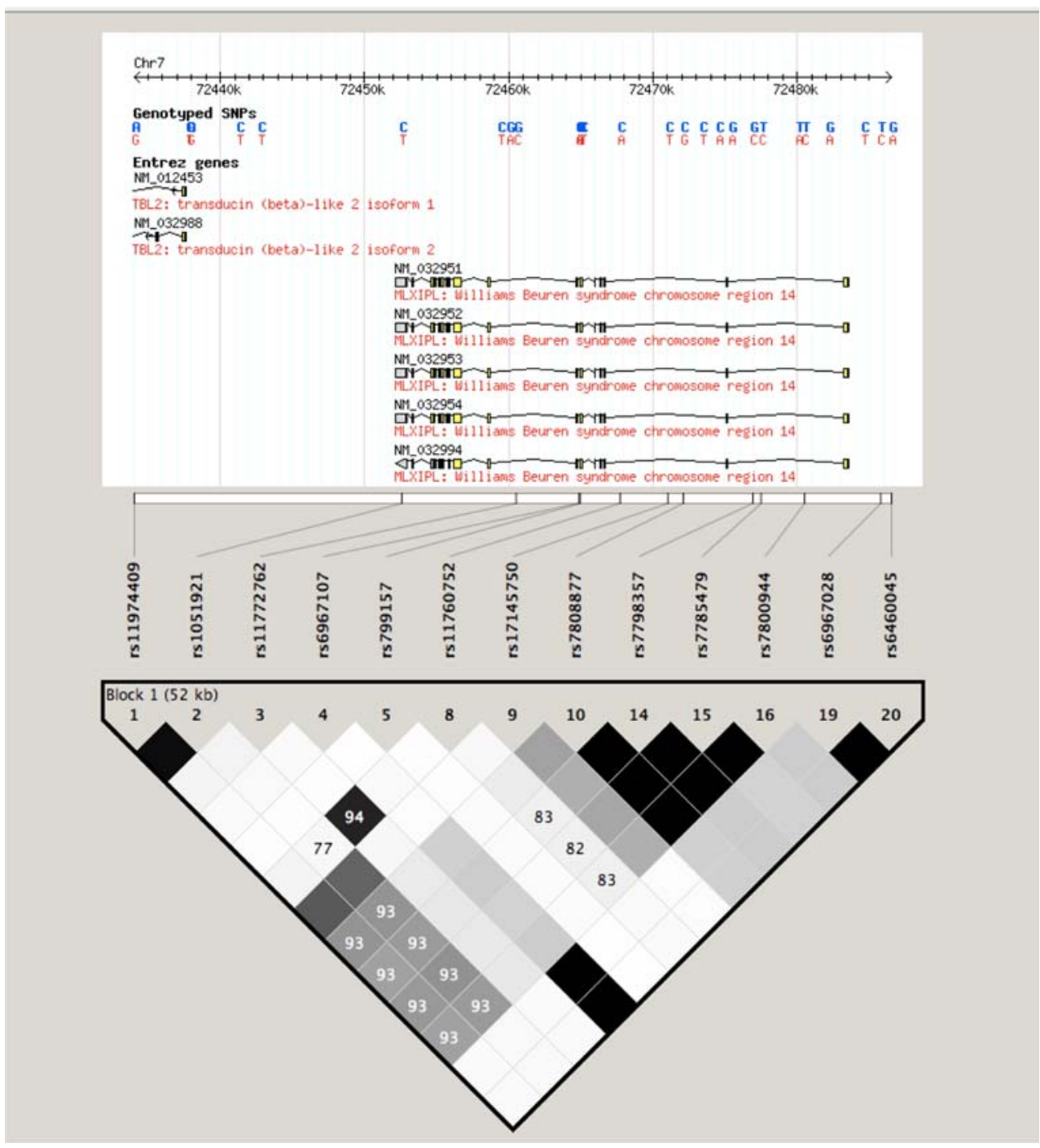

and $2.5 \mu \mathrm{l}$ of $2 \times$ master mix (Applied Biosystems) in a final volume of $5 \mu \mathrm{l}$. The thermocycling included 40 cycles with $30 \mathrm{~s}$ at $95^{\circ} \mathrm{C}$ followed by $60 \mathrm{~s}$ at $60^{\circ} \mathrm{C}$. PCR plates were read on an ABI PRISM 7900HT instrument (Applied Biosystems).

All samples that did not give a reliable result in the first round of genotyping were resubmitted to up to three additional rounds of genotyping. Data points that were still not filled after this procedure were left blank. Repeated quality control genotypes ( $8 \%$ of the total) showed an average concordance of $99.7 \%$.

\section{Statistical analysis}

The frequency distribution of genotypes was examined for cases and controls. For each SNP, deviation of genotype frequencies from the Hardy-Weinberg equilibrium was assessed in the controls by $\chi^{2}$ test (threshold of $P<0.01)$.
We used conditional logistic regression for multivariate analyses to assess the main effects of the genetic polymorphism on $\mathrm{BC}$ risk assuming dominant, recessive and codominant models of inheritance. The most common allele in the controls was held as the reference category in calculating the odds ratio (OR). All relative risk analysis were performed with the exclusion of cases with carcinomas in situ ( $n=93$ cases and 100 controls). For this analysis incomplete case-control sets could not be used and therefore were excluded. Subgroup analyses were performed based on menopausal status and age (with cutpoint at 50 or 55 years of age at diagnosis). Additional analyses were performed by including cases of carcinoma in situ, by excluding cases diagnosed shortly (6 months, 1 or 2 years) after blood drawing, or subjects who reported intake of hexogenous hormones.

Relationships of polymorphic gene variants with BMI were estimated by standard regression models and percentage of difference in geometric means in each genotype 
Fig. $3 S R E B F$ gene and its SNPs. For details, see Fig. 1

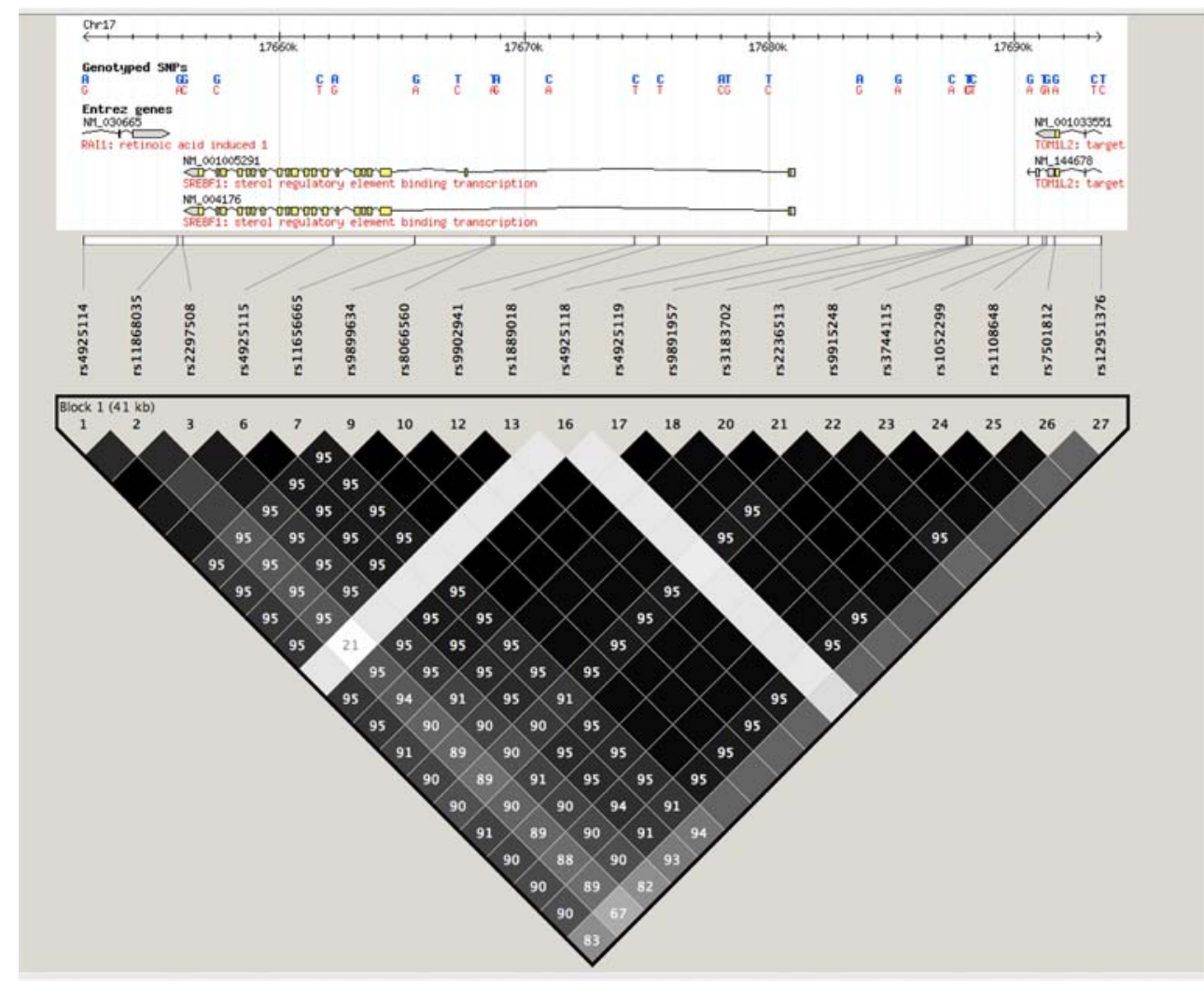

category compared to the major homozygote category was calculated. An additional analysis was performed by categorizing subjects with $\mathrm{BMI} \geq 30$ as obese $25 \leq \mathrm{BMI}<30$ as overweight and $<25$ as normal weight, and calculating odds ratios for obese or overweight versus normal weight with unconditional logistic regression. All BMI analyses were adjusted for age at blood donation, centre and BC case-control status. For this analysis we could use the genotypes of all the subjects, regardless of case-control and matching status.

Polymorphisms selected as tagging SNPs had a low level of residual linkage disequilibrium (on average $r^{2}=0.15$ for the FASN gene, $r^{2}=0.14$ for MLXIPL and $r^{2}=0.60$ for $S R E B F 1$ ), therefore we assumed that haplotypes were adequately captured by our tagging SNPs, and we did not attempt a haplotype analysis.

\section{Results}

The study explored the association between 20 DNA polymorphisms in three key genes involved in the fatty acid synthesis, namely FASN, MLXIPL and SREBF 1 and $\mathrm{BC}$ risk, as well as with BMI. We included 1,294 incident BC cases from the EPIC cohort and 2,452 matched controls in the study. Table 1 summarizes the baseline characteristics of cases and controls.
Table 1 Baseline characteristics of BC cases and control subjects

\begin{tabular}{lll}
\hline Variable & Cases & Controls \\
\hline Number & $1521^{\mathrm{a}}$ & $2555^{\mathrm{a}}$ \\
$\begin{array}{l}\text { Women with carcinoma in } \\
\quad \text { situ }\end{array}$ & $93^{\mathrm{a}}$ & $100^{\mathrm{a}}$ \\
Pre-menopausal women & $395^{\mathrm{a}}$ & \\
Peri-menopausal women & $139^{\mathrm{a}}$ & $755^{\mathrm{a}}$ \\
Post-menopausal women & $987^{\mathrm{a}}$ & $228^{\mathrm{a}}$ \\
Mean age at blood donation & $55.2(40.7-67.5)^{\mathrm{b}}$ & $1572^{\mathrm{a}}$ \\
Mean age at diagnosis & $57.5\left(40.9(43.0-70.0)^{\mathrm{b}}\right.$ & - \\
Height & $161.2(151.0-$ & $160.6(150.0-$ \\
& $172.0)^{\mathrm{b}}$ & $171.8)^{\mathrm{b}}$ \\
Weight & $67.6(51.7-89.0)^{\mathrm{b}}$ & $67.2(51.0-89.5)^{\mathrm{b}}$ \\
Body mass index & $26.0(20.3-34.4)^{\mathrm{b}}$ & $26.1(20.1-35.0)^{\mathrm{b}}$
\end{tabular}

\footnotetext{
${ }^{\text {a }}$ Number of subjects

b Mean (5th-95th percentiles)
}

We covered all the common genetic variants in the region of our candidate genes with a tagging approach. For the FASN gene, which is considerably larger than the two others, and located in a region of higher LD complexity, we integrated HapMap data with our own resequencing data. We found that all common (MAF $\geq 0.05)$ SNPs identified through resequencing were either already present in HapMap or tagged by HapMap SNPs, with the exception of 
Table 2 Associations between BC risk and SNPs in FASN, MLXIPL and SREBF1

\begin{tabular}{|c|c|c|c|c|c|c|c|c|c|c|c|c|}
\hline \multirow[t]{2}{*}{ Gene name } & \multirow[t]{2}{*}{ rs\# } & \multicolumn{2}{|c|}{ Homozygotes common allele } & \multicolumn{4}{|c|}{ Heterozygotes } & \multicolumn{4}{|c|}{ Homozygotes rare allele } & \multirow[t]{2}{*}{$P_{\text {trend }}^{\mathrm{c}}$} \\
\hline & & $\mathrm{Ca}^{\mathrm{a}}$ & $\mathrm{Co}^{\mathrm{a}}$ & $\mathrm{Ca}$ & $\mathrm{Co}$ & $\mathrm{OR}^{\mathrm{a}}$ & $95 \% \mathrm{CI}^{\mathrm{a}}$ & $\mathrm{Ca}$ & $\mathrm{Co}$ & OR & $95 \% \mathrm{CI}$ & \\
\hline \multirow[t]{11}{*}{ FASN } & rs2228309 & 404 & 676 & 633 & 1087 & 1.00 & $(0.85-1.17)$ & 238 & 439 & 0.92 & $(0.75-1.12)$ & 0.445 \\
\hline & rs4969465 & 730 & 1262 & 449 & 772 & 0.99 & $(0.86-1.15)$ & 83 & 131 & 1.10 & $(0.82-1.48)$ & 0.701 \\
\hline & rs2229425 & 962 & 1606 & 281 & 519 & 0.89 & $(0.75-1.05)$ & 23 & 46 & 0.83 & $(0.50-1.37)$ & 0.108 \\
\hline & rs1140616 & 349 & 573 & 637 & 1077 & 0.98 & $(0.83-1.16)$ & 299 & 567 & 0.87 & $(0.72-1.06)$ & 0.230 \\
\hline & rs2229422 & 575 & 1014 & 559 & 930 & 1.05 & $(0.90-1.22)$ & 136 & 238 & 1.01 & $(0.80-1.27)$ & 0.751 \\
\hline & rs4969486 & 1187 & 2048 & 85 & 144 & 1.00 & $(0.76-1.32)$ & 1 & 2 & 0.99 & $(0.09-10.9)$ & 0.978 \\
\hline & FASN_A0866 ${ }^{\mathrm{b}}$ & 781 & 1353 & 408 & 674 & 1.04 & $(0.90-1.21)$ & 42 & 76 & 0.96 & $(0.65-1.42)$ & 0.766 \\
\hline & rs4246445 & 669 & 1164 & 496 & 822 & 1.04 & $(0.90-1.20)$ & 98 & 173 & 0.95 & $(0.73-1.24)$ & 0.985 \\
\hline & rs4485435 & 877 & 1441 & 357 & 652 & 0.92 & $(0.78-1.07)$ & 34 & 74 & 0.79 & $(0.52-1.19)$ & 0.141 \\
\hline & rs11867806 & 607 & 1055 & 537 & 898 & 1.03 & $(0.89-1.20)$ & 117 & 204 & 1.00 & $(0.79-1.28)$ & 0.813 \\
\hline & rs12949488 & 814 & 1323 & 393 & 739 & 0.88 & $(0.76-1.03)$ & 57 & 97 & 0.99 & $(0.70-1.39)$ & 0.235 \\
\hline \multirow[t]{6}{*}{$M L X I P L$} & rs799157 & 1145 & 1939 & 91 & 148 & 1.05 & $(0.80-1.38)$ & 2 & 1 & 3.95 & $(0.36-43.5)$ & 0.552 \\
\hline & rs1051921 & 847 & 1419 & 336 & 611 & 0.91 & $(0.78-1.07)$ & 33 & 56 & 0.96 & $(0.61-1.50)$ & 0.317 \\
\hline & rs6967028 & 1027 & 1742 & 219 & 392 & 0.93 & $(0.77-1.12)$ & 12 & 29 & 1.05 & $(0.51-2.18)$ & 0.582 \\
\hline & rs7808877 & 659 & 1074 & 452 & 831 & 0.87 & $(0.75-1.02)$ & 99 & 147 & 1.07 & $(0.81-1.42)$ & 0.539 \\
\hline & rs11772762 & 775 & 1326 & 401 & 656 & 1.05 & $(0.89-1.23)$ & 46 & 78 & 1.00 & $(0.68-1.47)$ & 0.666 \\
\hline & rs 17145750 & 926 & 1556 & 293 & 515 & 0.95 & $(0.80-1.12)$ & 19 & 26 & 1.26 & $(0.69-2.29)$ & 0.836 \\
\hline \multirow[t]{3}{*}{ SREBF1 } & rs9899634 & 475 & 809 & 598 & 1011 & 1.02 & $(0.87-1.19)$ & 181 & 338 & 0.93 & $(0.72-1.20)$ & 0.644 \\
\hline & rs11868035 & 598 & 1011 & 545 & 937 & 1.01 & $(0.87-1.17)$ & 116 & 214 & 0.93 & $(0.72-1.20)$ & 0.744 \\
\hline & rs12951376 & 545 & 956 & 560 & 903 & 1.10 & $(0.95-1.28)$ & 133 & 244 & 0.98 & $(0.77-1.23)$ & 0.694 \\
\hline
\end{tabular}

${ }^{a} \mathrm{Ca}$, Cases; Co, Controls; OR, Odds ratios estimated by conditional logistic regression with matching of cases and controls for age at blood donation centre of recruitment, menopausal status at blood donation and past use of HRT; 95\% CI, 95\% confidence intervals

b Polymorphism FASN_A0866 is not represented in NCBI dbSNP. It is located in intron 20 of FASN and its flanking sequence is GCCCCGCCCC AGCCCCAGCC CAGTGCCCCC ACCCAAGTAT GCCGCACTCA [C/T] CCAGCCTGTC CCCACAGTGG CTGACGTGGT GGTGAGCAGG TGGCTGAGGG

${ }^{\mathrm{c}} P_{\text {trend }}$ for codominant model

one (FASN_A0866), which was genotyped on the complete series of cases and controls.

The genotype distributions at all SNPs typed in the EPIC samples were in Hardy-Weinberg equilibrium in controls, with non-significant $\chi^{2}$ values (data not shown).

The frequencies and distribution of the genotypes and the odds ratios for the association of each polymorphism with BC risk and BMI level are described in Tables 2 and 3 respectively. We observed no statistically significant association in the codominant, dominant or recessive models between the SNPs in the FASN, MLXIPL and $S R E B F 1$ genes and $\mathrm{BC}$ risk overall and stratified by age or menopausal status.

Additional analyses performed by including cases of carcinoma in situ, or excluding cases diagnosed shortly after blood drawing, or subjects who reported intake of exogenous hormones, showed essentially the same results as using all cases and controls (data not shown).

We performed also an analysis of the geometric means of BMI by SNP genotypes. We found that two SNPs in the FASN gene were associated with the level of BMI
(Table 3). SNP rs1140616 was associated with a higher mean of BMI ( $P$-trend 0.0061), while SNP FASN_A0866 was associated with a lower mean of BMI $(P$-trend 0.0270$)$ (Table 3).

There was no significant heterogeneity in association of any of the SNP variants with breast cancer with any category of BMI $\left(<25,25 \leq\right.$ BMI $<30$ or $\left.\geq 30 \mathrm{~kg} / \mathrm{m}^{2}\right)$. For SREBF1 and MLXIPL no associations with BMI were observed.

\section{Discussion}

We postulated that genetic polymorphisms in the FASN, MLXIPL and SREBF1 genes might play an important role in development of BC given their key function in lipogenesis. Up-regulation of genes involved in lipogenesis is a common feature of many cancers, as documented by the fact that many human tumor cells synthesize fatty acids instead of using fatty acids from the diet [40].

We tested in a large-scale association study, nested within the EPIC cohort, the involvement in BC risk of 
Table 3 Associations between BMI and SNPs in FASN, MLXIPL and SREBF1

\begin{tabular}{|c|c|c|c|c|c|c|c|c|}
\hline \multirow[t]{2}{*}{ Gene name } & \multirow[t]{2}{*}{ rs\# } & \multicolumn{2}{|c|}{ Homozygotes common allele } & \multicolumn{2}{|c|}{ Heterozygotes } & \multicolumn{2}{|c|}{ Homozygotes rare allele } & \multirow[t]{2}{*}{$P_{\text {trend }}^{\mathrm{c}}$} \\
\hline & & $N$ & BMI $(95 \% \mathrm{CI})^{\mathrm{a}}$ & $N$ & BMI $(95 \% \mathrm{CI})$ & $N$ & BMI $(95 \%$ CI $)$ & \\
\hline \multirow[t]{11}{*}{ FASN } & rs2228309 & 1236 & $25.96(25.71-26.22)$ & 1959 & $26.04(25.84-26.24)$ & 785 & $26.15(25.83-26.47)$ & 0.366 \\
\hline & rs4969465 & 2289 & $26.03(25.84-26.22)$ & 1415 & $26.04(25.80-26.27)$ & 240 & 26.11(25.54-26.69) & 0.863 \\
\hline & rs2229425 & 2935 & $26.02(25.85-26.19)$ & 940 & $26.06(25.77-26.35)$ & 81 & $26.12(25.13-27.10)$ & 0.770 \\
\hline & rs1140616 & 1031 & $25.73(25.45-26.00)$ & 1971 & $26.05(25.85-26.26)$ & 986 & $26.27(25.98-26.55)$ & 0.0071 \\
\hline & rs2229422 & 1812 & $26.06(25.84-26.27)$ & 1713 & $25.99(25.78-26.21)$ & 433 & $26.15(25.72-26.58)$ & 0.922 \\
\hline & rs4969486 & 3702 & $26.02(25.87-26.17)$ & 268 & $26.18(25.64-26.72)$ & 4 & 26.13(21.70-30.56) & 0.586 \\
\hline & FASN_A0866 ${ }^{\mathrm{b}}$ & 2504 & $26.15(25.97-26.33)$ & 1236 & $25.89(25.64-26.15)$ & 139 & $25.49(24.74-26.24)$ & 0.0275 \\
\hline & rs4246445 & 2107 & $25.93(25.74-26.13)$ & 1527 & $26.16(25.93-26.39)$ & 311 & $26.01(25.51-26.52)$ & 0.278 \\
\hline & rs4485435 & 2658 & $25.98(25.80-26.15)$ & 1164 & $26.15(25.88-26.41)$ & 127 & $26.32(25.53-27.11)$ & 0.200 \\
\hline & rs11867806 & 1915 & $26.01(25.81-26.22)$ & 1646 & $26.01(25.78-26.23)$ & 377 & $26.25(25.79-26.71)$ & 0.519 \\
\hline & rs12949488 & 2450 & $25.96(25.78-26.14)$ & 1311 & $26.13(25.88-26.38)$ & 179 & $26.24(25.57-26.90)$ & 0.214 \\
\hline \multirow[t]{6}{*}{$M L X I P L$} & rs799157 & 3613 & $26.06(25.91-26.21)$ & 272 & $25.89(25.35-26.43)$ & 5 & $25.40(21.42-29.38)$ & 0.506 \\
\hline & rs1051921 & 2674 & $26.01(25.84-26.19)$ & 1121 & $26.19(25.93-26.46)$ & 108 & $25.54(24.68-26.39)$ & 0.7440 \\
\hline & rs6967028 & 3210 & $26.06(25.89-26.22)$ & 694 & $25.94(25.60-26.28)$ & 36 & $27.04(25.56-28.52)$ & 0.990 \\
\hline & rs7808877 & 2063 & $25.95(25.75-26.15)$ & 1520 & $26.15(25.92-26.38)$ & 292 & $25.92(25.40-26.45)$ & 0.468 \\
\hline & rs11772762 & 2475 & $26.13(25.95-26.32)$ & 1243 & $26.02(25.76-26.27)$ & 146 & $25.30(24.56-26.04)$ & 0.0732 \\
\hline & rs 17145750 & 2901 & $25.95(25.78-26.12)$ & 937 & $26.28(25.98-26.57)$ & 54 & $26.04(24.83-27.25)$ & 0.0877 \\
\hline \multirow[t]{3}{*}{ SREBF1 } & rs9899634 & 1487 & $26.02(25.79-26.25)$ & 1855 & $26.02(25.81-26.23)$ & 610 & $26.21(25.85-26.57)$ & 0.475 \\
\hline & rs11868035 & 1872 & $26.14(25.93-26.34)$ & 1706 & $26.00(25.78-26.22)$ & 382 & $25.80(25.34-26.25$ & 0.152 \\
\hline & rs 12951376 & 1745 & $25.95(25.73-26.17)$ & 1710 & $26.10(25.88-26.32)$ & 444 & $26.07(25.65-26.50)$ & 0.403 \\
\hline
\end{tabular}

Statistically significant results $(P<0.05)$ are reported in bold

a $95 \%$ CI, 95\% confidence intervals

b Polymorphism FASN_A0866 is not represented in NCBI dbSNP. It is located in intron 20 of FASN and its flanking sequence is GCCCCGCCCC AGCCCCAGCC CAGTGCCCCC ACCCAAGTAT GCCGCACTCA [C/T] CCAGCCTGTC CCCACAGTGG CTGACGTGGT GGTGAGCAGG TGGCTGAGGG

${ }^{\mathrm{c}} P_{\text {trend }}$ for codominant model

common polymorphisms of the three genes. We did not observe any significant association between polymorphisms of FASN, MLXIPL and SREBF1 and an increased risk of cancer.

However, we did observe a statistically significant association between BMI and SNPs rs 1140616 and FAS_A0866 for the FASN gene. When we stratified subjects according to age or menopausal status, the two FASN SNPs also showed differential association with BMI, i.e., rs1140616 resulted associated only in younger/pre-menopausal women, while FAS_A0866 was associated with BMI only in older/postmenopausal subjects. This finding is relevant because, although we did not find an association with the final end point, BC, we found an association with an intermediate end point, since BMI is considered to be a risk factor for BC [35]. It is possible that the relatively modest change of BMI associated to FASN SNPs is not sufficient to have an impact on $\mathrm{BC}$ risk. In this view, it would be interesting to include these SNPs together with those of other genes in multifactorial models to predict $\mathrm{BMI}$ and $\mathrm{BC}$ risk.
In order to take into account the large number of tests performed in this project, we calculated for each gene the number of effective independent variables, $M_{\mathrm{eff}}$, by use of the SNP Spectral Decomposition approach [41, 42] (http:// gump.qimr.edu.au/general/daleN/SNPSpDsuperlite/). The $M_{\text {eff }}$ values for FASN, MLXIPL and SREBF1 are 8, 5, and 2 , respectively. The experiment-wide significance threshold is therefore $0.05 /(8+5+2)=0.0034$. If we use this threshold no association between SNPs and BMI remains significant.

The strengths of this study are a large sample size and use of a comprehensive tagging approach for examining FASN, MLXIPL and SREBF1 common variation.

Although over $97 \%$ of the EPIC subjects are estimated to be of Caucasian origin, differences in allelic frequencies across Europe could in theory cause confounding by population stratification. However, we did not observe major variations in allele frequencies across countries for the SNP studied here. Moreover, cases and controls were systematically matched for EPIC recruitment center. 
In conclusion, we have studied association of polymorphisms of three key genes in the lipogenesis pathway with $\mathrm{BC}$ risk and BMI within the EPIC study. We can confidently exclude a major role of these polymorphisms in BC risk, although two SNPs in FASN show an association with BMI that should be further evaluated in more comprehensive studies of polymorphisms and obesity.

Acknowledgments This study was supported by grant W81XWH04-1-0271 by the US Army Medical Research and Materiel Command. The EPIC study was funded by "Europe Against Cancer" Programme of the European Commission (SANCO); Ligue contre le Cancer (France); Société 3M (France); Mutuelle Générale de l'Education Nationale; Institut National de la Santé et de la Recherche Médicale (INSERM); German Cancer Aid; German Cancer Research Center; German Federal Ministry of Education and Research; Danish Cancer Society; Health Research Fund (FIS) of the Spanish Ministry of Health; the participating regional governments and institutions of Spain; Cancer Research UK; Medical Research Council, UK; the Stroke Association, UK; British Heart Foundation; Department of Health, UK; Food Standards Agency, UK; the Wellcome Trust, UK; Greek Ministry of Health; Greek Ministry of Education; Italian Association for Research on Cancer; Italian National Research Council; Dutch Ministry of Public Health, Welfare and Sports; Dutch Ministry of Health; Dutch Prevention Funds; LK Research Funds; Dutch ZON (Zorg Onderzoek Nederland); World Cancer Research Fund (WCRF); Swedish Cancer Society; Swedish Scientific Council; Regional Government of Skane, Sweden; Norwegian Cancer Society. The authors wish to thank Dr Alun Thomas (Department of Biomedical Informatics, University of Utah School of Medicine, Salt Lake City, Utah) for providing assistance with the Java SnpScreen software.

\section{References}

1. Augustin LS, Dal Maso L, La Vecchia C et al (2001) Dietary glycemic index and glycemic load, and breast cancer risk: a casecontrol study. Ann Oncol 12:1533-1538. doi:10.1023/A:101317 6129380

2. Hankinson SE, Willett WC, Colditz GA et al (1998) Circulating concentrations of insulin-like growth factor-I and risk of breast cancer. Lancet 351:1393-1396. doi:10.1016/S0140-6736(97) 10384-1

3. Kaaks R (1996) Nutrition, hormones, and breast cancer: is insulin the missing link? Cancer Causes Control 7:605-625. doi: 10.1007/BF00051703

4. Kaaks R, Lukanova A (2001) Energy balance and cancer: the role of insulin and insulin-like growth factor-I. Proc Nutr Soc 60:91106. doi: $10.1079 /$ PNS200070

5. Kaaks R, Lukanova A (2002) Effects of weight control and physical activity in cancer prevention: role of endogenous hormone metabolism. Ann N Y Acad Sci 963:268-281

6. Muti P, Quattrin T, Grant BJ et al (2002) Fasting glucose is a risk factor for breast cancer: a prospective study. Cancer Epidemiol Biomarkers Prev 11:1361-1368

7. Toniolo P, Bruning PF, Akhmedkhanov A et al (2000) Serum insulin-like growth factor-I and breast cancer. Int $\mathrm{J}$ Cancer 88: 828-832. doi:10.1002/1097-0215(20001201)88:5<828::AID-IJC 22>3.0.CO; $2-8$

8. Kaaks R, Lundin E, Rinaldi S et al (2002) Prospective study of IGF-I, IGF-binding proteins, and breast cancer risk, in northern and southern Sweden. Cancer Causes Control 13:307-316. doi: 10.1023/A:1015270324325
9. Krajcik RA, Borofsky ND, Massardo S et al (2002) Insulin-like growth factor I (IGF-I), IGF-binding proteins, and breast cancer. Cancer Epidemiol Biomarkers Prev 11:1566-1573

10. Li BD, Khosravi MJ, Berkel HJ et al (2001) Free insulin-like growth factor-I and breast cancer risk. Int J Cancer 91:736-739. doi: 10.1002/1097-0215(200002)9999:9999<::AID-IJC1111>3.0.CO;2-\#

11. Bianchini F, Kaaks R, Vainio H (2002) Overweight, obesity, and cancer risk. Lancet Oncol 3:565-574. doi:10.1016/S14702045(02)00849-5

12. Key T, Appleby P, Barnes I et al (2002) Endogenous sex hormones and breast cancer in postmenopausal women: reanalysis of nine prospective studies. J Natl Cancer Inst 94:606-616

13. Lahmann PH, Schulz M, Hoffmann K et al (2005) Long-term weight change and breast cancer risk: the European prospective investigation into cancer and nutrition (EPIC). $\mathrm{Br} \mathrm{J}$ Cancer 93:582-589. doi:10.1038/sj.bjc.6602763

14. Weiderpass E, Gridley G, Persson I et al (1997) Risk of endometrial and breast cancer in patients with diabetes mellitus. Int $\mathrm{J}$ Cancer 71:360-363. doi:10.1002/(SICI)1097-0215(19970502)71: $3<360:$ :AID-IJC9>3.0.CO;2-W

15. Kuhajda FP, Jenner K, Wood FD et al (1994) Fatty acid synthesis: a potential selective target for antineoplastic therapy. Proc Natl Acad Sci USA 91:6379-6383. doi:10.1073/pnas.91.14.6379

16. da Silva Xavier G, Rutter GA, Diraison F et al (2006) ChREBP binding to fatty acid synthase and L-type pyruvate kinase genes is stimulated by glucose in pancreatic beta-cells. J Lipid Res 47:2482-2491. doi:10.1194/jlr.M600289-JLR200

17. Andreolas C, da Silva Xavier G, Diraison F et al (2002) Stimulation of acetyl-CoA carboxylase gene expression by glucose requires insulin release and sterol regulatory element binding protein 1c in pancreatic MIN6 beta-cells. Diabetes 51:25362545. doi:10.2337/diabetes.51.8.2536

18. Diraison F, Parton L, Ferre P et al (2004) Over-expression of sterol-regulatory-element-binding protein-1c (SREBP1c) in rat pancreatic islets induces lipogenesis and decreases glucosestimulated insulin release: modulation by 5-aminoimidazole-4carboxamide ribonucleoside (AICAR). Biochem J 378:769-778. doi:10.1042/BJ20031277

19. Rufo C, Teran-Garcia M, Nakamura MT et al (2001) Involvement of a unique carbohydrate-responsive factor in the glucose regulation of rat liver fatty-acid synthase gene transcription. J Biol Chem 276:21969-21975. doi:10.1074/jbc.M100461200

20. Yang YA, Morin PJ, Han WF et al (2003) Regulation of fatty acid synthase expression in breast cancer by sterol regulatory element binding protein-1c. Exp Cell Res 282:132-137. doi: 10.1016/S0014-4827(02)00023-X

21. Alo PL, Visca P, Trombetta G et al (1999) Fatty acid synthase (FAS) predictive strength in poorly differentiated early breast carcinomas. Tumori 85:35-40. doi:10.1159/000015275

22. Milgraum LZ, Witters LA, Pasternack GR et al (1997) Enzymes of the fatty acid synthesis pathway are highly expressed in in situ breast carcinoma. Clin Cancer Res 3:2115-2120

23. Pizer ES, Wood FD, Heine HS et al (1996) Inhibition of fatty acid synthesis delays disease progression in a xenograft model of ovarian cancer. Cancer Res 56:1189-1193

24. Rashid A, Pizer ES, Moga M et al (1997) Elevated expression of fatty acid synthase and fatty acid synthetic activity in colorectal neoplasia. Am J Pathol 150:201-208

25. Shurbaji MS, Kalbfleisch JH, Thurmond TS (1996) Immunohistochemical detection of a fatty acid synthase (OA-519) as a predictor of progression of prostate cancer. Hum Pathol 27:917921. doi:10.1016/S0046-8177(96)90218-X

26. Alo PL, Visca P, Marci A et al (1996) Expression of fatty acid synthase (FAS) as a predictor of recurrence in stage I breast carcinoma patients. Cancer 77:474-482. doi:10.1002/(SICI)10970142(19960201)77:3<474::AID-CNCR8>3.0.CO;2-K 
27. Menendez JA, Lupu R (2007) Fatty acid synthase and the lipogenic phenotype in cancer pathogenesis. Nat Rev Cancer 7:763777. doi: $10.1038 / \mathrm{nrc} 2222$

28. Swinnen JV, Roskams T, Joniau S et al (2002) Overexpression of fatty acid synthase is an early and common event in the development of prostate cancer. Int J Cancer 98:19-22. doi:10.1002/ ijc. 10127

29. Kuhajda FP (2000) Fatty-acid synthase and human cancer: new perspectives on its role in tumor biology. Nutrition 16:202-208. doi:10.1016/S0899-9007(99)00266-X

30. Kuhajda FP, Pizer ES, Li JN et al (2000) Synthesis and antitumor activity of an inhibitor of fatty acid synthase. Proc Natl Acad Sci USA 97:3450-3454. doi:10.1073/pnas.050582897

31. Pizer ES, Jackisch C, Wood FD et al (1996) Inhibition of fatty acid synthesis induces programmed cell death in human breast cancer cells. Cancer Res 56:2745-2747

32. Pizer ES, Thupari J, Han WF et al (2000) Malonyl-coenzyme-A is a potential mediator of cytotoxicity induced by fatty-acid synthase inhibition in human breast cancer cells and xenografts. Cancer Res 60:213-218

33. Thupari JN, Pinn ML, Kuhajda FP (2001) Fatty acid synthase inhibition in human breast cancer cells leads to malonyl-CoAinduced inhibition of fatty acid oxidation and cytotoxicity. Biochem Biophys Res Commun 285:217-223. doi:10.1006/bbrc. 2001.5146

34. Menendez JA, Colomer R, Lupu R (2005) Why does tumorassociated fatty acid synthase (oncogenic antigen-519) ignore dietary fatty acids? Med Hypotheses 64:342-349. doi:10.1016/j. mehy.2004.07.022
35. Key TJ, Verkasalo PK, Banks E (2001) Epidemiology of breast cancer. Lancet Oncol 2:133-140. doi:10.1016/S1470-2045(00) 00254-0

36. Riboli E, Hunt KJ, Slimani N et al (2002) European Prospective Investigation into Cancer and Nutrition (EPIC): study populations and data collection. Public Health Nutr 5:1113-1124. doi: 10.1079/PHN2002394

37. Shattuck-Eidens D, Oliphant A, McClure M et al (1997) BRCA1 sequence analysis in women at high risk for susceptibility mutations. Risk factor analysis and implications for genetic testing. JAMA 278:1242-1250. doi:10.1001/jama.278.15.1242

38. Carlson CS, Eberle MA, Rieder MJ et al (2004) Selecting a maximally informative set of single-nucleotide polymorphisms for association analyses using linkage disequilibrium. Am J Hum Genet 74:106-120. doi:10.1086/381000

39. de Bakker PI, Yelensky R, Pe'er I et al (2005) Efficiency and power in genetic association studies. Nat Genet 37:1217-1223. doi:10.1038/ng1669

40. Medes G, Thomas A, Weinhouse S (1953) Metabolism of neoplastic tissue. IV. A study of lipid synthesis in neoplastic tissue slices in vitro. Cancer Res 13:27-29

41. Li J, Ji L (2005) Adjusting multiple testing in multilocus analyses using the eigenvalues of a correlation matrix. Heredity 95:221227. doi:10.1038/sj.hdy. 6800717

42. Nyholt DR (2004) A simple correction for multiple testing for single-nucleotide polymorphisms in linkage disequilibrium with each other. Am J Hum Genet 74:765-769. doi:10.1086/383251 